\title{
An Approach to Simulate the Speed of Non-Motorized Vehicles With Respect to Various Parameters
}

\author{
Siddharth.Purohit* Ujjal.Chattaraj \\ Department of Civil Engineering -NIT Rourkela,Rourkela ,769008, Odisha, India
}

\begin{abstract}
An attempt has been made to study the variation in speed of a non-motorized vehicle with respect to three different parameters and to propose a model to simulate the speed of an NMV from the data obtained from experimental results. Fuzzy logic was used as a tool for linguistic classification of the premise variable in this model. As far as the simulation results are concerned it was seen that speed value obtained experimentally and obtained from the model are almost same. It was studied that all the three parameters have a significant impact on the speed of a non-motorized vehicle in a mixed traffic. It was seen that speed decreases with increase in number of PCUs in the same strip, speed decreases with increase in number of PCUs in the adjacent strips and speed increase when distance from the road edge increases.
\end{abstract}

Keywords - NMV, MV, PCU, fuzzy logic, mixed traffic.

\section{INTRODUCTION}

In Asian countries like India mostly a mixed traffic flow is found. Which means the flow consist of all type of vehicles like cycle, rickshaw, car, bus etc. In Indian cities the share of non-motorized transport (NMT) at peak hours is almost more than 50 per cent. Different cities have different patterns of NMT use. Every public transport mode of transport involves access trips by NMT at each end because never the less at the end at least they need to walk. So, non-motorized mode of traffic plays a vital role in meeting travel demand in countries like India. Importance of non-motorized vehicles in India can be found in Sarana 2010 [11].The study of mixed traffic is quite complicated. In a mixed flow when number of non-motorized vehicles increases of vehicles leads to many problems like conflicts at intersections, it affects the speed and flow of other vehicles. It significantly lowers or reduces the capacity also leads to various safety problems. Therefore a separate track for flow of nonmotorized traffic is used in various developed counties like USA, in countries like India this is practically not possible due to lack of space. So in that case a proper study of non-motorized vehicle characteristics should be done along with study of how these NMV are affected in the mixed traffic. Hence study of both NMVs movement and it effect on motorized mode are taken into account in the project. 'Non-Motorized Vehicles' (NMVs) is refereed to different types of pedal powered vehicles used in the Indian subcontinent. These include different shapes and sizes of bicycles and tricycles. Tricycles are used to carry goods and passengers; these are commonly called as cycle rickshaws. The various dimensions of NMVs are adopted from Bicycle Infrastructure Design Manual for Indian Subcontinent by Arora 2009 [1].

Various literatures from the past have been studied and few have been considered for this study purpose. Oketch 2003 [5], developed a special model to investigate the effects of various non-conventional vehicles on stream performance including lane capacity and saturation flows. This paper says that for such heterogeneous streams had reduced link capacities and lane saturation flows in comparison to homogenous flows with private cars only, although the trends were not always consistent. Rahman and Nakamura 2005 [10], introduced a method for estimating passenger car equivalents(PCE) for non-motorized vehicle based on speed reduction of passenger cars in the mixed flow due to the presence of non-motorized vehicles from the observed data collected from two mid-block sections of Dhaka, Bangladesh. Similar study was done by Rahman and et al. 2004 [9] to develop an estimation method of passenger car equivalent of rickshaws and auto rickshaws at signalized intersections by a macroscopic approach.Rahman and et al. 2003 [8] also made a study on the effect of nonmotorized vehicles on urban road traffic characteristics from four mid-block sections of Dhaka, Bangladesh and concluded that non-motorized vehicles have adverse effect on fundamental traffic parameters. Pan and Kerali 2007 [6] conducted a research on the effects of non-motorized traffic flow on motorized vehicle speeds on the basis of field observations of vehicle speeds on Chinese roads and observed linear relationship between motorized vehicle speeds and non-motorized traffic flow under a range of motorized traffic flow volumes. Dianhai and et al. 2007 [3] made a study on bicycle conversion factor calibration at two-phase intersections in mixed traffic flows from various cities in china. They proposed model to calculate the through bicycle traffic and left-turn bicycle traffic conversion factors in intersections where bicycles and motor vehicles share the same road. Liang and et al. 2011 [12] made a study for calculating straight lane capacity under mixed traffic conditions in China. The First Discharge Headway (FDH) was applied as a novel to improve Stop Line Method 
model, and the influencing factors of FDH were analysed. From various literatures it was found that presence of non-motorized vehicle in a mixed traffic affects the flow significantly. Following are the main objective of the study:

- To study the variation in speed of NMV with respect to number of PCUs in the same strip, number of PCUs in the adjacent strip, distance of the test vehicle from the road edge.

- To propose a model to simulate the speed of NMV with respect to mentioned parameters.

\section{Experimental Observation}

\subsection{Field observation, Data Collection and Data Extraction}

Based on data obtained from various locations of a city called Rourkela in India various studies have been done in this project. Two locations were selected specially for this study. All the data were collected by a video camera for 30 minutes interval. A section on each road was selected having sufficient number of nonmotorized traffic. Length of the section was considered to be $5 \mathrm{~m}$. Using some marking tools the four corners of the area was marked and the video of the section was taken. A schematic view is presented in Fig. 1. All the data were recorded by using the video camera and later decoded in the computer by playing the video with the help of KM player @ 25 frames per sec.A cellophane paper was pasted on the computer screen and the four corners were marked and joined with help of a white board marker. This was done because although the actual shape of the section is rectangular but when captured in a camera its shape gets deformed; somewhat trapezoidal depending on the position of camera.For the study of variation of speed with respect to various parameters, the section area was dividedinto equal number of strips, presented in Fig. 2. Then with respect to test vehicle (NMV), number of vehicles of different class in same and the both adjoining strip of strip in which test vehicle is there was noted. This process starts when test vehicle enters the section and this ends when test vehicle leaves the section. All vehicle classes were converted to one unit i.e. PCUin accordance with IRC-86 [4]. Speed of the test vehicle was calculated by ratio between times spent by it in the section to the distance covered (i.e. length of section + length of the test vehicle). Then graph between speed of test vehicle and the three parameters were plotted. Along with this fundamental diagram and lateral occupancy were also studied, more on this can be found in Purohit et al. 2014 [7].

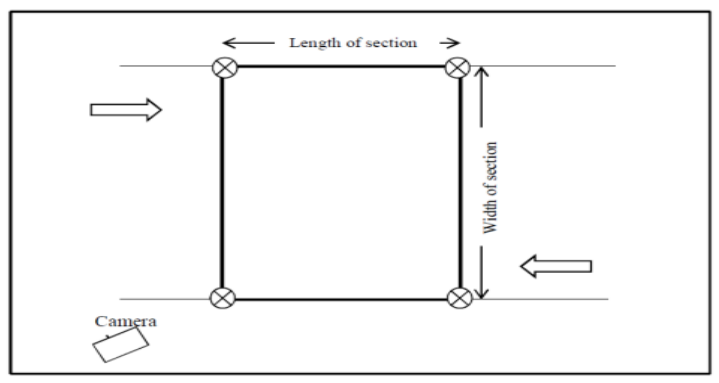

Fig. 1:Schematic diagram showing the road cross section

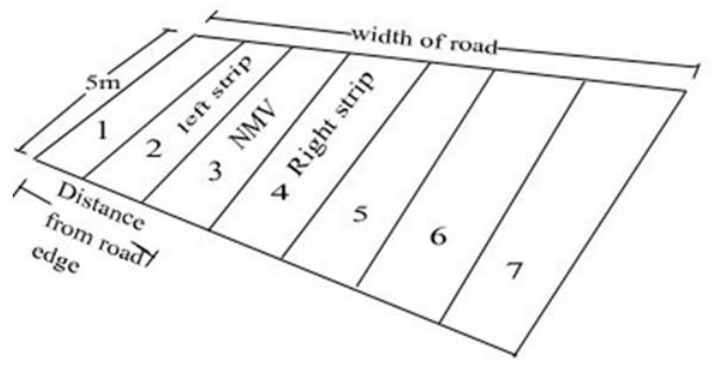

Fig. 2: Road section study of speed with respect to various parameters

\section{Proposed model}

\subsection{Basic structure of the proposed model}

This gives an idea about the generalized structure of the proposed model. This model is to simulate the speed versus various parameters; an experimental observation was done to see how speed of a non-motorized vehicle varies according to various parameters like

- Number of PCUs in same strip.

- Number of PCUs in both adjacent strips. 
- $\quad$ Distance of test vehicle from road edge.

These 3 parameters are the input parameters, which are responsible for the speed of the test vehicle as an output of the model. A fuzzy inference model was developed. Reference for fuzzy inference model was taken fromChattaraj et al. 2010 [2]. Fig. 3 gives a complete idea about the model. Each part of the system is described one by one in the following sub sections.

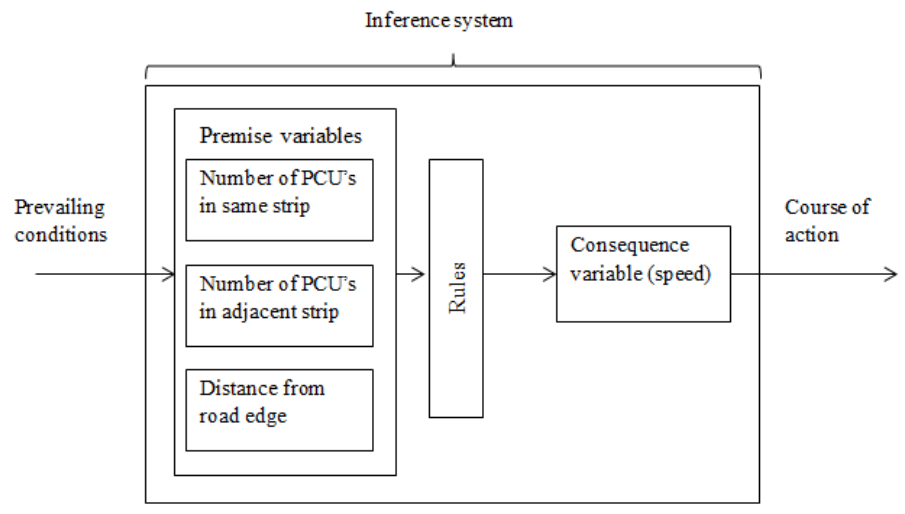

Fig. 3: Fuzzy inference system

\subsection{Premise variables and their linguistic classification}

From the prevailing condition we got three input parameters as premise variables. They are as follows;

Number of PCUs in same strip. $\left(\mathrm{s}_{\mathrm{z}}\right)$

Number of PCUs in both adjacent strips. $\left(\mathrm{a}_{\mathrm{z}}\right)$

Distance of test vehicle from road edge. $\left(\mathrm{d}_{\mathrm{z}}\right)$

Number of PCUs in same strip $\left(s_{z}\right)$ :It is the number of vehicles (in terms of PCU) in the same strip in which our test vehicle is moving. It is linguistically classified into 3 groups, namelylarge number, moderate number, few numbers. The three linguistic classes are described as fuzzy sets defined on $s_{z}$. Shown in Fig. 4. The membership functions are shown in equation number 1 to 3

For few number

$$
\mu_{f}\left(s_{z}\right)=\left\{\begin{array}{c}
1 ; s_{z} \leq s_{z}^{1} \\
\frac{s_{z}^{2}-s_{z}}{s_{z}^{2}-s_{z}^{1}} ; s_{z}^{1}<s_{z} \leq s_{z}^{2} \\
0 ; s_{z} \geq s_{z}^{2}
\end{array}\right.
$$

For moderate number

$$
\mu_{m}\left(s_{z}\right)=\left\{\begin{array}{c}
0 ; s_{z} \leq s_{z}^{1} \\
\frac{s_{z}-s_{z}^{1}}{s_{Z}^{2}-s_{Z}^{1}} ; s_{z}^{1}<s_{z} \leq s_{z}^{2} \\
\frac{s_{z}^{3}-s_{z}}{s_{Z}^{3}-s_{z}^{2}} ; s_{z}^{2}<s_{z} \leq s_{z}^{3} \\
0 ; s_{z} \geq s_{z}^{3}
\end{array}\right.
$$

For large number

$$
\mu_{l}\left(s_{z}\right)=\left\{\begin{array}{c}
0 ; s_{z} \leq s_{z}^{2} \\
\frac{s_{z}-s_{z}^{2}}{s_{z}^{3}-s_{z}^{2}} ; s_{z}^{2}<s_{z} \leq s_{z}^{3} \\
1 ; s_{z} \geq s_{z}^{3}
\end{array}\right.
$$

It may be noted that the values of the limits $s_{z}^{1}, s_{z}^{2}, s_{z}^{3}$ can be decided through a trial and error process. The Number of PCUs in both adjacent strips $\left(\mathrm{a}_{\mathrm{z}}\right)$ : It is the number of vehicles (in terms of PCU) in both left and right strip adjacent to the strip in which the test vehicle is moving. It is divided into three linguistic classes, namely, high number, moderate number, less number. The three linguistic classes are described as fuzzy 
sets defined on $a_{z}$. Shown in Fig 5. The membership functions are shown in equation number 4 to 6.For less number

$$
\mu_{l}\left(a_{z}\right)=\left\{\begin{array}{c}
1 ; a_{z} \leq a_{z}^{1} \\
\frac{a_{z}^{2}-a_{z}}{a_{z}^{2}-a_{z}^{1}} ; a_{z}^{1}<a_{z} \leq a_{z}^{2} \\
0 ; a_{z} \geq a_{z}^{2}
\end{array}\right.
$$

For moderate number

$$
\mu_{m}\left(a_{z}\right)=\left\{\begin{aligned}
0 ; & a_{z} \leq a_{z}^{1} \\
\frac{a_{z}-a_{z}^{1}}{a_{z}^{2}-a_{z}^{1}} ; & a_{z}^{1}<a_{z} \leq a_{z}^{2} \\
\frac{a_{z}^{3}-a_{z}}{a_{z}^{3}-a_{z}^{2}} ; & a_{z}^{2}<a_{z} \leq a_{z}^{3} \\
0 ; & a_{z} \geq a_{z}^{3}
\end{aligned}\right.
$$

For high number

$$
\mu_{h}\left(a_{z}\right)=\left\{\begin{array}{c}
0 ; a_{z} \leq a_{z}^{2} \\
\frac{a_{z}-a_{z}^{2}}{a_{z}^{3}-a_{z}^{2}} ; a_{z}^{2}<a_{z} \leq a_{z}^{3} \\
1 ; a_{z} \geq a_{z}^{3}
\end{array}\right.
$$

It may be noted that the values of the limits $a_{z}^{1}, a_{z}^{2}, a_{z}^{3}$ can be decided through a trial and error process.

The Distance of test vehicle from road edge $\left(\mathrm{d}_{\mathrm{z}}\right)$ : It is the distance between the left edges of road to the center line of the strip in which the test vehicle is moving. It is divided into three linguistic classes, namely, near, far, very far. The three linguistic classes are described as fuzzy sets defined on $d_{z}$. Shown in Fig. 6.The membership functions are shown in equation number 7 to 9.

For near

$$
\mu_{n}\left(d_{z}\right)=\left\{\begin{array}{c}
1 ; d_{z} \leq d_{z}^{1} \\
\frac{d_{z}^{2}-d_{z}}{d_{z}^{2}-d_{z}^{1}} ; d_{z}^{1}<d_{z} \leq d_{z}^{2} \\
0 ; d_{z} \geq d_{z}^{2}
\end{array}\right.
$$

For far

$$
\mu_{f}\left(d_{z}\right)=\left\{\begin{array}{c}
0 ; d_{z} \leq d_{z}^{1} \\
\frac{d_{z}-d_{z}^{1}}{d_{z}^{2}-d_{z}^{1}} ; d_{z}^{1}<d_{z} \leq d_{z}^{2} \\
\frac{d_{z}^{3}-d_{z}}{d_{z}^{3}-d_{z}^{2}} ; d_{z}^{2}<d_{z} \leq d_{z}^{3} \\
0 ; d_{z} \geq d_{z}^{3}
\end{array}\right.
$$

For very far

$$
\mu_{v f}\left(d_{z}\right)=\left\{\begin{array}{c}
0 ; d_{z} \leq d_{z}^{2} \\
\frac{d_{z}-d_{z}^{2}}{d_{z}^{3}-d_{z}^{2}} ; d_{z}^{2}<d_{z} \leq d_{z}^{3} \\
1 ; d_{z} \geq d_{z}^{3}
\end{array}\right.
$$

It may be noted that the values of the limits $d_{z}^{1}, d_{z}^{2}, d_{z}^{3}$ can be decided through a trial and error process. 


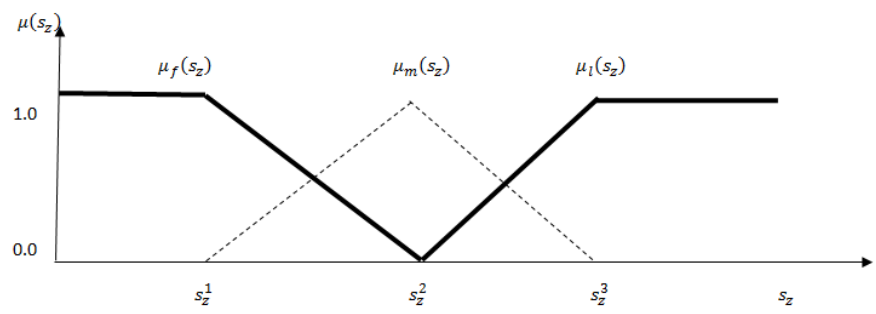

Fig. 4: Membership functions for sets of number of PCUs in same strip

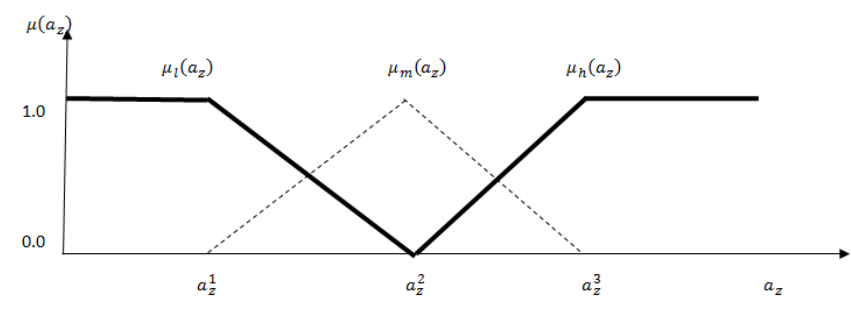

Fig.5: Membership functions for sets ofnumber of PCUs in both adjacent strips

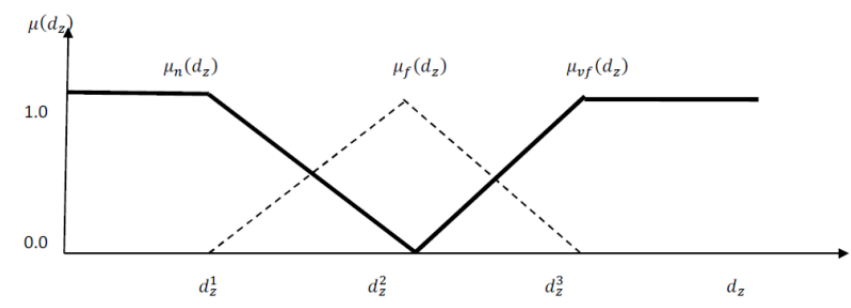

Fig.6: Membership functions for sets of distance of test vehicle from road edge

\subsection{Consequence variable}

The consequence variable in this fuzzy inference system represents the speed at which the vehicle will move. This is taken on a scale of $\mathrm{S}$. As there are 27 rules hence there are $27 \mathrm{~S}$ values i.e. $\mathrm{S}_{1}, \mathrm{~S}_{2}, \mathrm{~S}_{3} \ldots . . \mathrm{S}_{27}$. The values of $S_{1}, S_{2} \ldots . . S_{27}$ were decided as per the speed data obtained experimentally.

\subsection{Rules of the fuzzy inference system}

The fuzzy inference system developed here relates the premise variables to the consequence variable, through a set of rules. In this inference system there are total 27 rules each relating a particular combination of the premise variables to some $\mathrm{S}$ value. Fig. 7 shows the mapping between premise and consequence variable. For clarity all 27 rules are not shown.

The rules are based on following principles as found from the preliminary experimental study;

- S decreases as number of PCU's in the same strip increases.

- S decreases as number of PCU's in the adjacent strip increases.

- $\mathrm{S}$ increases as distance from road edge increases.

If any input data satisfies more than one rule then weighted average is taken as per equation number 10.

$$
\mathrm{D}(\mathrm{k})=\sum\left(\frac{w_{r, k}}{\sum w_{r, k}} S_{r}\right)
$$

Where, $\mathrm{w}_{\mathrm{r}, \mathrm{k}}$ is the weight of the $\mathrm{r}^{\text {th }}$ membership Subset with input set $\mathrm{k}$.

$\mathrm{S}_{\mathrm{r}}$ is the consequence. Weight of a membership subset, $\mathrm{w}_{\mathrm{r}, \mathrm{k}}=\min \left\{\mu\left(s_{z}\right), \mu\left(a_{z}\right), \mu\left(d_{z}\right)\right\}$ 


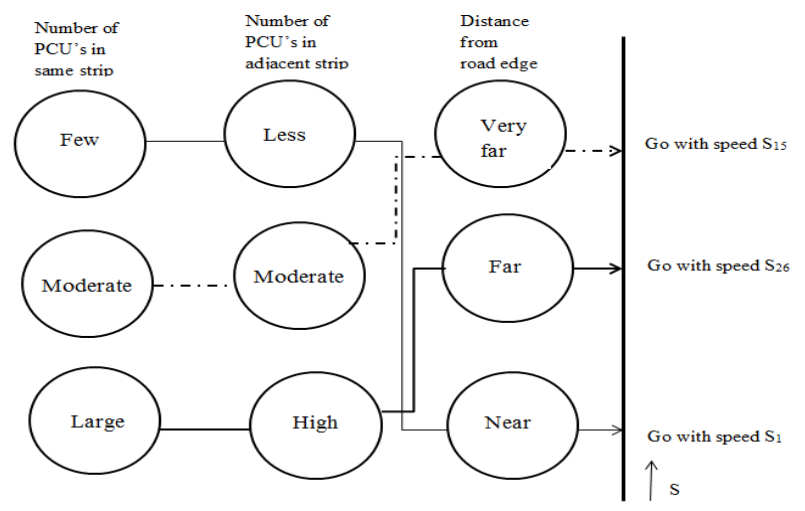

Fig. 7: Mapping between premise variable and consequence variable.

\subsection{Simulation}

As per the structure of the proposed model is shown above a computer simulation or a program was developed. The simulation was done using $\mathrm{C}++$.After defining all the parameters all the input data were inserted. Then the program automatically calculates the membership values for the particular set of inputs. As there are 27 rules, so weight for each membership subset (27 subsets) for a particular input set was calculated. Then weighted average of output value of each membership subset was calculated. This gives the final output value for that particular input set. Similarly the above procedure was followed for each input set and finally the parameters were printed in an output file. The complete procedure is presented in form of a flow chart in Fig. 8 .

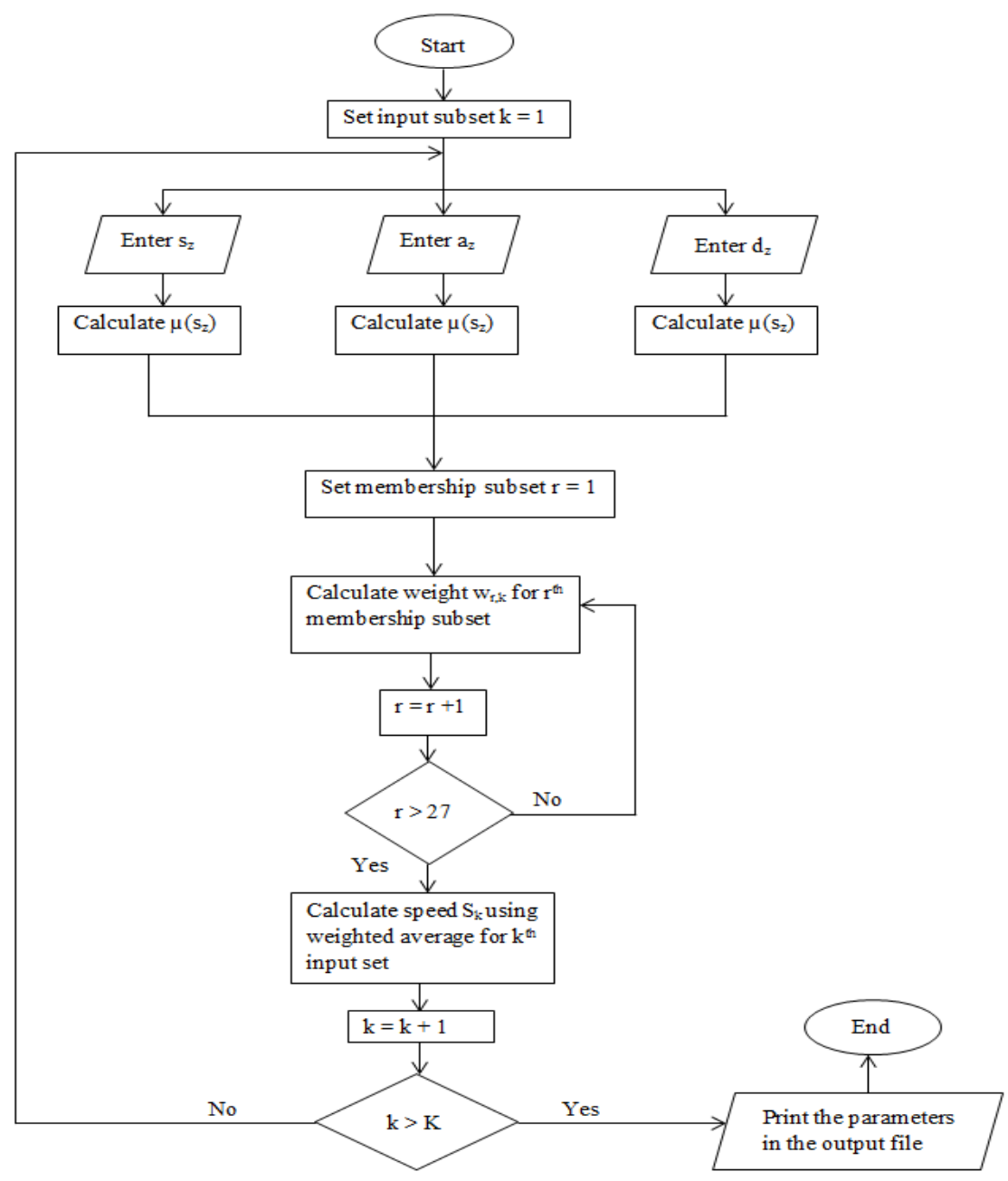

Fig. 8: Flow chart for the simulation 
The model was calibrated by using the data obtained from location 1 . Calibration refers to the various membership values taken i.e. the values of $s_{z}^{1}, s_{z}^{2}, s_{z}^{3}, a_{z}^{1}, a_{z}^{2}, a_{z}^{3}, d_{z}^{1}, d_{z}^{2}, d_{z}^{3}$. It also refers to the value adopted for the consequence variable i.e. the various $S$ values. It also refers to the mapping between the premise and consequence variables i.e. the 27 rule adopted to get output.

\subsubsection{Calibration of the membership values}

As stated before the model was calibrated according to the data obtained from road towards Rourkela main market. So the maximum and minimum values of each premise variable were noted from the experimental data. On a trial basis the values of $s_{z}^{1}, s_{z}^{2}, s_{z}^{3}$ were taken in the following manner;

$$
\begin{aligned}
& s_{z}^{1} \simeq s_{z} \min +1 / 4\left(s_{z} \max -s_{z} \min \right) \\
& s_{z}^{2} \simeq s_{z} \min +2 / 4\left(s_{z} \max -s_{z} \min \right) \\
& s_{z}^{3} \simeq s_{z} \min +3 / 4\left(s_{z} \max -s_{z} \min \right)
\end{aligned}
$$

Where, $s_{Z} \min$ is the minimum $s_{Z}$ value obtained from experimental data.

$s_{Z}$ maxis the maximum $s_{Z}$ value obtained from experimental data.

Similar procedure was adopted for the other two premise variable. But it was seen this does not give the exact value, so to adjust the output values three values for all the limits was taken, one less than the adopted value and a bit higher than the adopted value. So now all $s_{z}^{1}, s_{z}^{2}, s_{z}^{3}, a_{z}^{1}, a_{z}^{2}, a_{z}^{3}, d_{z}^{1}, d_{z}^{2}, d_{z}^{3}$ have three values each. Then various combinations of the values were taken, but at a time only one element will change and rest eight elements will have the same value. So in total there will be $3^{9}$ set of combinations.

$$
\left[\begin{array}{lll}
s_{z}^{1} & s_{z}^{2} & s_{z}^{3} \\
a_{z}^{1} & a_{z}^{2} & a_{z}^{3} \\
d_{z}^{1} & d_{z}^{2} & d_{z}^{3}
\end{array}\right]
$$

For each combination a set of speed value was obtained. Then sum of the $\mathrm{R}^{2}$ error value was found out i.e. square of the difference between experimental and simulated speed value was found out and its total was calculated.The combination with least $\mathrm{R}^{2}$ error value was finally adopted. Practically running a program for $3^{9}$ times is slight impossible, so after running the program for about 150 times the combination with least $\mathrm{R}^{2}$ error value was finally adopted.

\subsubsection{Calibration of consequence variables ( $\mathrm{S}$ values)}

$\mathrm{S}$ value indicates the speed value or value of the consequence variable. As per section 3.4.2 of Bicycle Infrastructure Design Manual for Indian Sub-continent maximum speed of a cycle in main cycle rout is $30 \mathrm{kmph}$ and in other routs with mixed traffic is $20 \mathrm{kmph}$. In this project unit taken is in meters per second so maximum speed should be $5.5 \mathrm{~m}$ per sec. but on a safe side the maximum speed is taken as $8 \mathrm{~m}$ per sec and minimum speed as $1 \mathrm{~m}$ per sec.

\subsection{Model validation}

After calibration of the model i.e. after fixing all membership values of premise variable, defining all 27 rule and after fixing the values of consequence variable; it's time to check the model. Hence the model was validated by entering the data obtained from $2^{\text {nd }}$ location as input parameter, rest of the value mentioned above were not changed. It was seen that the results in form of speed data are almost same as that obtained by experimentally.

\section{RESULTS AND DISCUSSION}

From the data collected from both the locations, data was extracted and speed of a non-motorized vehicle against all three parameters were plotted, presented in Fig. 9 to Fig. 14. It was found that the percentage of NMV in both the location was $48 \%$ and $39 \%$ respectively. While density of the traffic was $5.87 \mathrm{PCU} / \mathrm{m}$ and 6.35 PCU/m respectively. Due to increased number of NMV the flow reduces considerably and hence speeds of both non-motorized and motorized vehicles were affected. From the experimental results (Fig. 9 and Fig. 12) it was seen that when number of vehicles in terms of PCU in the same strip increases the speed of the test vehicle decreases in order to avoid a longitudinal or head on collision and to maintain a safe distance from other vehicles. Fig. 10 and Fig. 13 shows the variation of speed of test vehicle with respect to number of vehicles present in both the adjacent strips, here also with increase in vehicle number the test vehicles reduces its speed in order to avoid a lateral or side collision. But due to these two parameters the NMV test vehicle is trying to overtake other vehicles from right hand side and increasing their speed. Therefore speed increases when distance from the left side road edge increases, presented in Fig. 11 and Fig.14. 
Further this observation was used to model the speed of the test vehicle with respect to the three mentioned parameters. Fig. 9 to Fig 11 shows the simulation results from location 1, whose data was used to calibrate the model. Fig 12 to Fig. 14 shows the simulation results for location 2, whose data was used to validate the model.

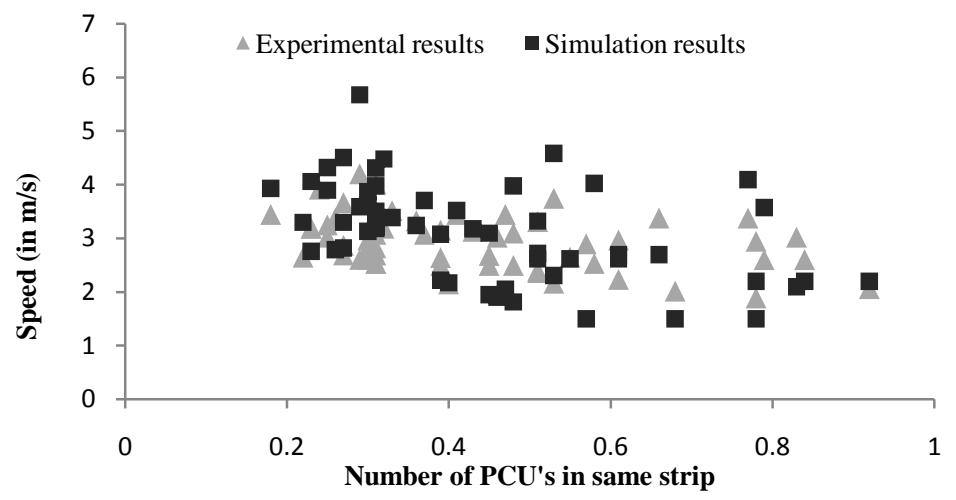

Fig. 9: Speed versus number of PCU's in same strip for location 1

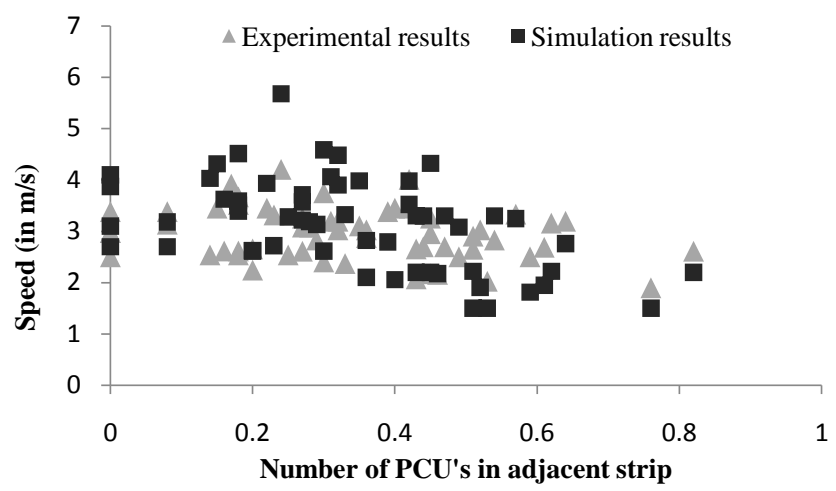

Fig. 10: Speed versus number of PCU's in alternate strip for location 1

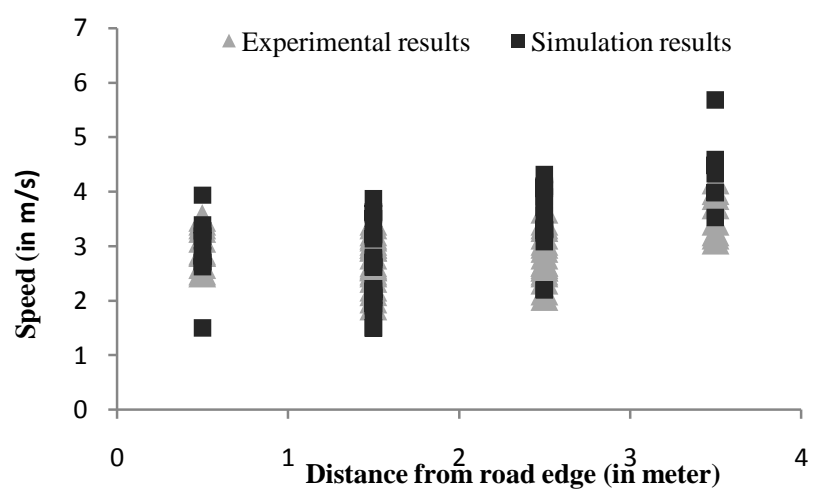

Fig. 11: Speed versus distance from road edge for location 1

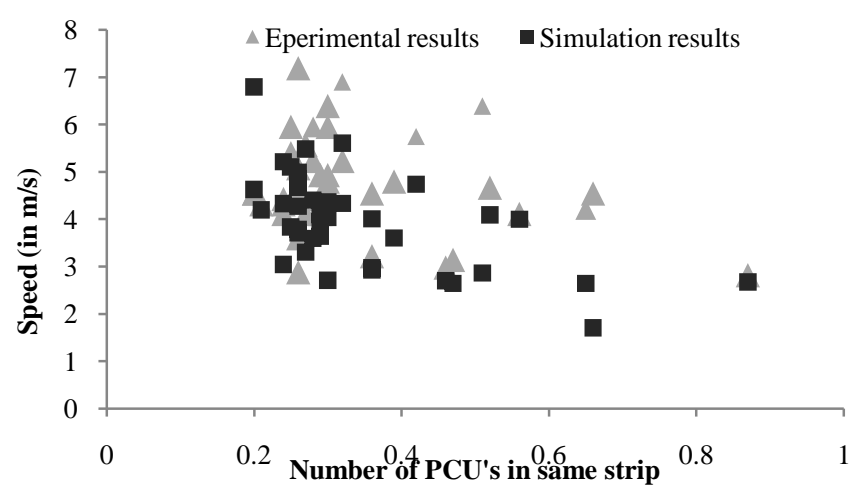

Fig. 12:Speed versus number of PCU's in same strip for location 2 


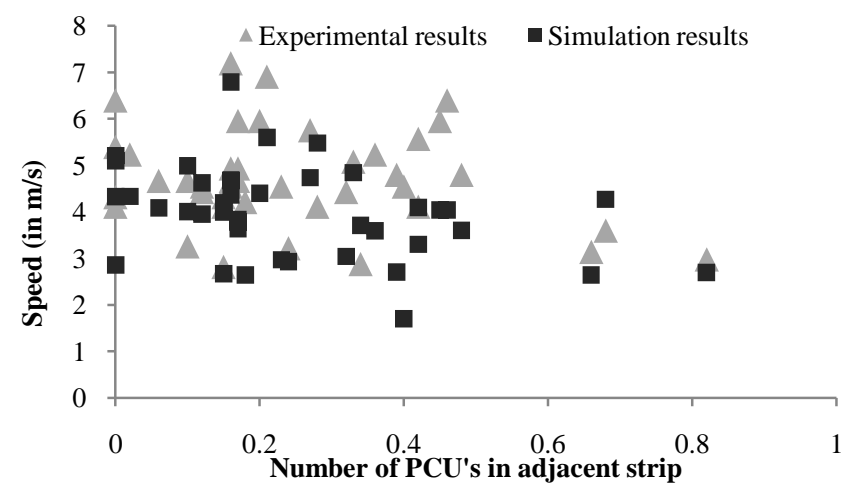

Fig. 13: Speed versus number of PCU's in adjacent strip for location 2

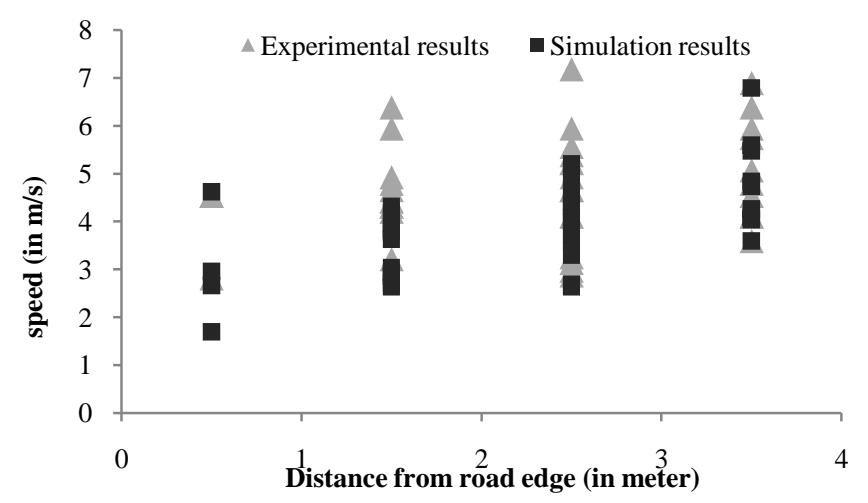

Fig. 14: Speed versus distance from road edge for location 2

\section{CONCLUSION}

From the experimental observation of speed versus various parameters it can be concluded that speed of the non-motorised test vehicles

1.Decreases when number of PCUs in same strip increases.

2. Decreases when number of PCUs in adjacent strip increases.

3. Increases when distance from the road edge increases.

First two properties are in order to avoid head on and lateral collision, but due to reduction in speed of NMV the flow and capacity of the entire traffic movement gets adversely affected. While when NMV increases its speed when it moves from left hand side of the road in order to overtake the vehicle present in same and adjacent strips, but this leads to a serious concern that as the road section is a 2 way flow, the NMV are trying to block the movement of vehicles from opposite direction. The NMV try to spread them throughout entire stretch of road laterally. This leads to a conjunction of traffic in opposite direction, which may lead to collision or accident as well. As far as the simulation results are concerned it was seen that speed value obtained experimentally and obtained from the model are almost same. So the model can be used for roads with mixed traffic with single lane of flow and non-motorized vehicle content up to $50 \%$.Solution to this issue is to either separate cycle tack or marking on the existing road to separate the non-motorized vehicle movement at peak hours. Further scope of work include to make this model more generalised by suggesting an exact variation in speed value with reference to mentioned three parameters (and any other extra parameter) from which any one can conclude with an exact solution to the issue. For this accident data of the locations are also needed.

\section{REFERENCES}

[1] Arora, A. (2009). Bicycle Infrastructure Design Manual for Indian Subcontinent. Suma summit, New Delhi, pp. 8-18.

[2] Chattaraj U., Chakroborty P., Seyfried, A.(2010). Empirical Studies on Pedestrian Motion through Corridors of Different Geometries, Proceedings (CD ROM) of Transportation Research Board 89th Annual meeting, Washington D.C. (U.S.A.), pp. 10-14.

[3] Dianhai, W., Chuyan, L., Chunguang, J. and Guohua, W. (2007). Bicycle conversion factor calibration at two-phase intersections in mixed traffic flows. Tsinghua science and technology, vol. 12, pp. 318-323.

[4] Indian road congress, Geometric design standards for urban roads in plains, IRC: 86-1983 
[5] Oketch, T.(2003). Modelled Performance Characteristics of Heterogeneous Traffic Streams Containing NonMotorized Vehicles. Transportation Research Board 82 ${ }^{\text {nd }}$ Annual Meeting, Washington, D.C., CD-ROM.

[6] Pan, Y. and Kerali, H.(1999). Effect of nonmotorized transport on motorized vehicle speeds in China. Transportation Research Record: Journal of the Transportation Research Board, (1695), pp.34-41.

[7] Purohit, S., Chattaraj, U. and Panda, M.(2014). Experimental Study of Non-motorized Vehicle Characteristics and Its Effect on Mixed Traffic. International Journal for Traffic and Transport Engineering, 4(4), pp.425-436.

[8] Rahman, M., Okura, I. and Nakamura, F.(2003).Analysis of effects of non-motorized vehicles on urban road traffic characteristics. Proceedings of infrastructure planning, vol.28 (CD-ROM)

[9] Rahman, M.M., Okura, I. and Nakamura, F.(2004). Effects of rickshaws and auto-rickshaws on the capacity of urban signalized intersections. IATSS research, 28(1), pp.26-33.

[10] Rahman, M.M. and Nakamura, F. (2005). Measuring passenger car equivalents for nonmotorized vehicle (rickshaws) at mid-block sections. Journal of the Eastern Asia Society for Transportation Studies, 6, pp.119-126.

[11] Sarna, A.C.(1991). Importance of Nonmotorized Transport in India. Transportation Research Record, (1294).

[12] Liang, X., Zhili, L.I.U. and Kun, Q.I.A.N.(2011). Capacity analysis of signalized intersections under mixed traffic conditions. Journal of Transportation Systems Engineering and Information Technology, 11(2), pp.91-99. 